\title{
EXPERIÊNCIA NA FORMAÇÃO INICIAL: CONSTRUINDO SIGNIFICADOS PARA AVALIAÇÃO
}

\author{
Adriana Varani \\ Universidade Estadual de Campinas \\ Ana Paula Souza Brito \\ Rede Municipal de Sorocaba e \\ Universidade Estadual de Campinas \\ Frediana Vezzaro Medeiros \\ Universidade Federal de São Carlos \\ Adriana Aparecida Alves da \\ Silva \\ Universidade de Sorocaba
}

\begin{abstract}
Resumo
O presente artigo relata uma experiência na formação inicial de professores que se pretendeu integradora entre diferentes áreas e disciplinas, mediadas pela discussão do campo da avaliação educacional. Para tanto foi construído e implementado um projeto de pesquisa com os estudantes do curso de Pedagogia de uma Universidade Federal no ano de 2012 cuja pretensão foi investigar os usos, abusos e discursos dos processos avaliativos vividos no campo escolar por diferentes sujeitos. A avaliação educacional foi tomada em dois níveis: o da aprendizagem e o das políticas de avaliação em larga escala. $\mathrm{O}$ artigo tem como objetivo refletir sobre os significados atribuídos ao conceito de avaliação pelos estudantes, através de suas produções resultantes da experiência. Dos significados produzidos, ressaltamos: as contradições vividas pelos sujeitos no que se refere ao campo da avaliação escolar; os processos de responsabilização dos sujeitos pelo desempenho obtido. Tal experiência também nos proporcionou o repensar de nossa prática avaliativa na formação inicial.
\end{abstract}

Palavras-chave: Avaliação de ensino; Formação de professores; Pesquisa-ensino. 


\title{
EXPERIENCE IN TEACHER EDUCATION: CONSTRUCTING MEANINGS FOR EVALUATION
}

\begin{abstract}
This paper reports an experience in teacher education that was intended integrator between different areas and disciplines, mediated by the discussion of the educational evaluation. For both built and implemented a research project with students of Pedagogy from a Federal University in 2012 whose intention was to investigate the uses, abuses and speeches evaluative processes experienced in the field of education by different subjects. The educational evaluation was reflected on two levels: the learning and the policies of large-scale evaluation. The article aims to reflect on the meanings attributed to the concept of evaluation by students through their productions resulting from experience. The meanings produced, we emphasize: the contradictions experienced by subjects in relation to the field of educational evaluation; accountability processes of the subject by the performance obtained. This experience also gave us rethinking our evaluation practice in initial formation.
\end{abstract}

Keywords: Educational evaluation; Teacher education; Educational research. 


\section{Introdução}

Muitas experiências no campo da formação de professores em diferentes modalidades demonstram as potencialidades e os limites dos processos para a melhoria do quadro atual da atuação pedagógica. Dar a ver tais experiências implicam um passo a mais neste movimento que é o de promover as necessárias reflexões para a sua retomada. E o "dar a ver" pode ser materializado pelo seu registro e seu diálogo com outros e, desta forma, nos fazermos também outro em nosso trabalho. É esta a pretensão deste artigo: dar a ver uma experiência no campo da formação de professores que se pretendeu, de certa forma, integradora entre diferentes áreas da educação, mediados pela discussão do campo da avaliação educacional, num trabalho de pesquisa.

O movimento descrito e refletido a seguir ocorreu no segundo semestre letivo de 2012, no curso de Pedagogia de uma Universidade Federal. Tal curso é noturno, teve início em 2009, e faz parte do Programa de Reestruturação e Expansão das Universidades Federais - REUNI. Em sua grade curricular, encontram-se as disciplinas denominadas de Pesquisas e Práticas Pedagógicas (PPP's) que compõem os seis primeiros semestres do curso. O objetivo geral das PPP's é reunir reflexões acerca da teoria e da prática educativa de maneira interdisciplinar, buscando a articulação entre as outras disciplinas do semestre em curso. Vale destacar que entre as atividades propostas nas disciplinas de Pesquisas e Práticas Pedagógicas o trabalho de investigação e pesquisa em educação é um eixo significativo para a formação do educador-pesquisador.

A possibilidade de tomar o eixo integrador no quarto perfil do curso, através da disciplina Pesquisa e Prática Pedagógica IV, se materializou pela presença de disciplinas que tomariam a avaliação como discussão. Dessa forma, a PPP IV esteve em constante diálogo com a disciplina de Didática III, cujo objetivo era discussão de avaliação educacional. A disciplina de Política Educacional também subsidiou o trabalho, à medida que tomou como um de seus temas de estudo as políticas de avaliação em larga escala.

Olh@res, Guarulhos, v. 2, n. 1, p. 253-269. Maio, 2014. 
Para materialização do princípio do trabalho de reflexão interdisciplinar e consequentemente deste diálogo, foi constituído uma proposta de pesquisa, realizada pelos estudantes desta turma da Pedagogia, sobre os discursos, usos e abusos das práticas avaliativas na vida de sujeitos escolarizados. E dois eixos da avaliação "saltavam aos olhos" dos estudantes: as marcas dos instrumentos de avaliação nas pessoas e as políticas de avaliação em larga escala. Tais eixos, consequentemente, se tornaram objeto de reflexão e de olhar no processo de levantamento de dados que será descrito ao longo do artigo.

Muito embora integre uma matriz curricular que, como tal, sustenta-se na concepção do processo de formação de docentes fragmentado em disciplinas, o componente curricular PPP foi formulado a partir do ponto de vista da interdisciplinaridade. É, de fato, uma experiência que quer tornar-se retroalimentadora da dinâmica do processo de formação de Pedagogos desenvolvido na UFSCar-Sorocaba. Propor-se como interdisciplinar requer um reconhecimento da complexidade que tal tarefa carrega e assumir uma compreensão do termo a despeito da diversidade de olhares produzidos sobre o tema. Alguns autores nos orientam na tomada de posicionamento sobre interdisciplinaridade, dentre eles Gallo (2000), Morin (2000) e Pombo (s/d). Trazemos a ideia de que a organização da escola e, consequentemente, a organização do conhecimento em seu interior acompanhou a lógica da construção do conhecimento disciplinar (GALLO, 2000) e da hiperespecialização. No campo da educação vários problemas e temas diversos demandam resolução que vão além de uma única disciplina. A interdisciplinaridade se propõe a colocar as disciplinas em inter-relação, estabelecendo entre si uma relação recíproca.

Deverá então entender-se (interdisciplinaridade) qualquer forma de combinação entre duas ou mais disciplinas com vista a compreensão de um objecto a partir da confluência de pontos de vista diferentes e tendo como objectivo final a elaboração de uma síntese relativamente ao objecto comum. A interdisciplinaridade implica, portanto, alguma reorganização do processo de ensino/aprendizagem e supõe um trabalho continuado de cooperação dos professores envolvidos. (POMBO, s/d, p. 13) 
No campo da prática que está sendo construída, a discussão se complexifica um pouco mais, pois ocorre dentro dos limites tanto institucionais (criação de disciplinas) quanto da razão científica pela qual fomos formados. O Projeto Pedagógico do Curso de Pedagogia da UFSCar - Sorocaba construiu um pequeno passo na articulação e possível transposição disciplinar futura, o que requereria um movimento mais amplo como de superação da disciplina (GALLO, 2000). Na experiência em questão, a avaliação educacional foi temática a ser compreendida em diferentes perspectivas por diferentes áreas de conhecimento, a saber: política, da didática, da psicologia, metodologia, currículo. A despeito do desenvolvimento de algumas disciplinas, conhecimentos perpassados em outros momentos de seu curso foram mobilizados pelos estudantes.

\section{Sobre o desenvolvimento do trabalho}

O desenvolvimento do trabalho com os alunos se constituiu, de início, na retomada do trabalho já realizado nas disciplinas de Pesquisas e Práticas Pedagógicas I, II e III, com vistas a visualizar e rememorar o caminho construído, destacando a continuidade do trabalho realizado na ênfase dos elementos da pesquisa que transversalizaram este caminho. Posteriormente, conduzimos o trabalho de maneira que os estudantes resgatassem as memórias referentes aos processos avaliativos presentes na trajetória escolar e produzissem uma linha do tempo individual com suas narrativas. Todos puderam ler e perpassar pelas histórias e experiências de avaliação uns dos outros. Ao longo das conversas sobre estas experiências, notou-se a preocupação com as marcas deixadas pelos processos avaliativos na vida dos sujeitos, especialmente do quanto ela foi negativa. Este peso negativo pode indicar as razões pelas quais escolheram as leituras evidenciadas nas produções finais, objetos de descrição e reflexão posterior.

Esse encaminhamento foi construído em parceria com os estudantes que, encontro a encontro, repensavam e refletiam sobre as práticas avaliativas vividas e relatadas entre todos do grupo. A ideia da relação entre a ação e a 
reflexão - proposta por Paulo Freire - foi um movimento contínuo no decorrer da disciplina e um dos objetivos alcançados na PPP IV.

Os alunos escolheram um sistema de avaliação em larga escala bem como um nível de ensino em que realizariam o levantamento de dados. Os estudos sobre os sistemas de avaliação em larga escala ocorreram na disciplina de Didática III, mas, especialmente, em Política Educacional. Os estudos mais sistemáticos sobre conceito de avaliação da aprendizagem ocorreram em Didática III. Nossa opção, dos estudantes do curso de Pedagogia e dos professores das disciplinas envolvidas, foi ouvir dos professores e alunos da educação básica de redes públicas de ensino suas experiências com avaliação da aprendizagem, bem como suas experiências referentes às avaliações em larga escala, dentre elas o ENEM, a Prova Brasil e o SARESP. Também houve o estudo de documentos oficiais sobre os sistemas de avaliação.

Para elaboração dos roteiros de entrevistas, nos valemos do livro "Pesquisa em Educação: abordagens qualitativas" de Ludke e André (1986). Neste espaço de construção dos roteiros, criamos um momento para discussão do papel da pesquisa em nossa formação, neste processo de constituição de nosso olhar investigador e questionador.

Com os dados em mãos, os grupos iniciaram a reflexão com vistas a elaborar um produto final para apresentação no Circo das PPP's ${ }^{1}$. Estes momentos de reflexão sobre o que os dados diziam juntamente com os estudos realizados, ocorreram durante os encontros semanais, sob a orientação das professoras de PPP IV.

A construção do produto final foi proposta de maneira que cada grupo pudesse escolher a forma de socialização da análise dos dados coletados. Foi assim que todos os grupos nos surpreenderam com suas produções criativas! De peça teatral a telejornal, e de aula a aula, no Laboratório de

\footnotetext{
${ }^{1}$ O Circo das PPPs é um evento realizado ao final de cada semestre para compartilhar, com todos os estudantes do curso, as produções realizadas nas PPP's ocorridas naquele semestre. Vale ressaltar que tal denominação tem um cunho político no contexto da realidade em que o curso de Pedagogia se insere dentro do Campus e dentro do Panorama geral do ensino superior. Há posicionamentos depreciativos em relação ao curso e no caso específico a disciplina de PPP, como denominação de que a aquele espaço se caracteriza como uma palhaçada no mundo acadêmico.

Olh@res, Guarulhos, v. 2, n. 1, p. 253-269. Maio, 2014.
} 
Práticas Pedagógicas (LaPed), o produto final foi se consolidando numa construção minuciosa, o que será descrito no item subsequente. O que nos interessa é que, ao tomar para si o movimento de decisão sobre o encaminhamento do trabalho em aula, os alunos se sentiram imersos num contexto de quebra com as amarras tradicionais da avaliação. Eles puderam definir quais seriam os instrumentos de avaliação que poderiam extrapolar aqueles usualmente conhecidos e poderiam colocar em ação seus conhecimentos em outras áreas de conhecimento e mobilizar suas potencialidades criativas.

\title{
2.Reflexões sobre avaliação que permearam nossa caminhada
}

Como já anunciado, o trabalho realizado ao longo do segundo semestre de 2012, teve como pressuposto realizar a integração de áreas de conhecimento que circulam, pelas disciplinas no perfil em questão, no curso de Pedagogia. Neste caso específico, o diálogo foi entre a possibilidade de pesquisa em avaliação educacional. E a avaliação educacional foi tomada em dois níveis: o da aprendizagem e o das políticas de avaliação pela larga escala.

É relevante iniciar esta discussão com um conceito de avaliação que extrapola o contexto educacional e que dá a dinâmica da superação do que se vive no contexto escolar, tomado de Luckesi

\begin{abstract}
$\mathrm{O}$ ato de avaliar, por sua constituição mesma, não se destina a um julgamento 'definitivo' sobre alguma coisa, pessoa ou situação, pois que não um ato seletivo. A avaliação se destina ao diagnóstico e, por isso, mesmo, à inclusão; destina-se à melhoria do ciclo da vida. Deste modo, por si, é um ato amoroso. Infelizmente, por nossas experiências históricosociais e pessoais, temos dificuldades em assim compreendê-la e praticá-la. (1995, p. 180)
\end{abstract}

Ao longo do semestre a condução foi no sentido de extrapolar o olhar reducionista a que o processo de escolarização nos levou a constituir que é o da avaliar enquanto instrumento de controle, classificação, verificação e, consequentemente, punição. 
Sabemos que essas considerações relacionadas à avaliação estão circunscritas nas práticas pedagógicas institucionalizadas historicamente, marcadas pela avaliação como finalização de um processo. Freitas (2009) nos aponta que essa visão está presente nos manuais escolares numa perspectiva linear: primeiro o desenvolvimento da aprendizagem e, posteriormente, a verificação. O autor, ainda, enfatiza que esta posição de avaliação caracteriza-se pela classificação e seleção, uma vez que centraliza o processo somente na verificação do que o aluno aprendeu ou não.

Vale retomar, aqui, que a avaliação da aprendizagem está direcionada a reflexão sobre o processo de aprendizagem e, também (porque não), da "ensinagem" em que aluno e professor estão envolvidos. A avaliação da aprendizagem está preocupada com o processo que ocorre em aula no trato com o conhecimento. Ela pode, segundo Luckesi (1995), se manifestar por duas práticas diferentes. O que nos interessa neste momento é que, ao trabalharmos com o conceito de avaliação da aprendizagem, nosso princípio foi o da reflexão da prática de avaliação preocupada com a transformação e não com a reprodução do que está dado. E, nesta perspectiva,

Ela deverá estar atenta aos modos de superação do autoristarismo e ao estabelecimento da autonomia do educando (...) e deverá manifestar-se como um mecanismo de diagnóstico da situação tendo em vista o avanço e o crescimento e não a estagnação disciplinadora do aluno. (LUCKESI, 1995, p. 32)

E o avanço se refere ao processo também de aquisição de conhecimento.

Essa forma de realizar e conceber a avaliação pressupõe um novo olhar para a organização da escola e do próprio sistema escolar. Isso porque não é possível pensar em processo, aprendizagem, desenvolvimento, autonomia e reflexão numa lógica de seriação, na qual há uma divisão dos alunos por ano e verificações de aprendizagem para averiguar domínio de conhecimentos para aprová-los ou retê-los. ${ }^{2}$

As considerações já apresentadas nos possibilitam refletir sobre a importância da avaliação no contexto escolar, principalmente no que se refere às avaliações externas, em evidência no sistema educacional

\footnotetext{
${ }^{2}$ Não é nossa intenção neste momento discorrer sobre esta temática, o que valeria um artigo a parte. Para maior compreensão ver Freitas (2003).

Olh@ res, Guarulhos, v. 2, n. 1, p. 253-269. Maio, 2014.
} 
brasileiro. Com o argumento relacionado à falta de dados referentes ao rendimento escolar, o MEC assume um papel avaliador e orientador das políticas da educação básica a partir da década de 1980. Muitos sistemas de avaliação em larga escala são implantados: o SAEB (Sistema de Avaliação da Educação Básica) em seguida a Prova Brasil, depois a construção de um novo indicador, o IDEB - Índice de Desenvolvimento da Educação Básica. Para o Ensino Médio, é criado o ENEM. ${ }^{3}$

Questões referentes ao ranqueamento das escolas, ênfase no produto, premiações e punições, reforçam a visão classificatória e controladora da avaliação destes sistemas imersas em contextos políticos específicos, uma vez que desconsideram as condições efetivas de realização do trabalho pedagógico desenvolvido em cada contexto escolar.

O que se pretende, aqui, é refletir sobre um processo avaliativo que destaque os conhecimentos produzidos coletivamente, possibilitando novas formas de compreensão da realidade e amplie as possibilidades de superação das atuais condições. E foi esta a pretensão ao longo do trabalho com os alunos no curso de Pedagogia neste projeto específico.

\section{O processo vivido ao longo do trabalho: entre desejos e ações}

A partir desta perspectiva, no campo da avaliação educacional e da aprendizagem, nos dirigimos ao trabalho em sala de aula. Como a disciplina iria ser avaliada? Esta era a questão central, uma vez que nosso objeto de estudo e de pesquisa era justamente este processo de avaliação. Teríamos que definir instrumentos e fazer uma média final e romper com o que acreditávamos sobre o princípio dialógico da avaliação, sobre o princípio de revisão de caminhos e não de verificação e classificação?

Os alunos se manifestaram dizendo que não seria interessante criar instrumentos, mas pensar numa forma em que todo o processo fosse avaliado. Fizemos ainda um desafio, os próprios alunos avaliariam o processo. O "como" ainda seria objeto de reflexão.

\footnotetext{
${ }^{3}$ Para compreensão do processo de criação destes sistemas algumas leituras são recomendadas, dentre elas Gatti (2009) e Freitas (2009).

Olh@res, Guarulhos, v. 2, n. 1, p. 253-269. Maio, 2014.
} 
Essa ação pode ser analisada a partir da perspectiva de Freitas (2009) que destaca a importância de se considerar a avaliação justaposta aos objetivos, orientando todo o processo pedagógico. Isso demanda refletir sobre os processos de avaliação mais utilizados nas escolas (testes, provas, questões orais, tarefas) que não representam as únicas possibilidades de avaliar.

É importante, então, ampliarmos o nosso conceito de avaliação para incluir práticas avaliativas que estejam além daquelas usualmente enfatizadas e que se limitam ao processo instrucional de verificação de conteúdos. Há mais que isso nos processos de avaliação. (FREITAS, 2009, p. 26)

Nesse sentido, podemos dizer que a avaliação envolve um processo dialógico, no qual professor e aluno se relacionam na apropriação do saber. A avaliação passa a exigir do professor, segundo Hoffman (2000, p. 56), "uma reflexão aprofundada a respeito das formas como se dá a compreensão do educando sobre o objeto do conhecimento". E esta reflexão estava se materializando, naquele momento, pelas intervenções dos alunos no trabalho das professoras.

\section{Reflexão sobre as produções finais}

O trabalho de reconhecer a discussão da avaliação no campo da prática pedagógica (realizado pelas disciplinas de Didática III e PPP IV) e tomar os dois níveis de avaliação - larga escala e aprendizagem - demonstrou o quão complexa é tal relação. E, para dar a dimensão desta complexidade, tomamos os trabalhos apresentados pelos estudantes, destacando o como eles significaram os conceitos circulados. Após a vivência de construção do trabalho ao longo do semestre e das diferentes produções pertinentes ao trabalho na finalização do processo, os alunos elaboraram suas reflexões finais a partir de distintas formas. Antes de refletir sobre esta significação, vamos descrever, brevemente, como se caracterizou cada uma das produções finais.

A primeira produção, que aqui chamaremos de Grupo 1, refere-se a um trabalho de pesquisa realizado junto aos internos de uma penitenciária. Os estudantes tinham como objetivo investigar quais as marcas da escola e, em 
especial, dos processos avaliativos, eles carregavam, bem como compreender que significados produziam a partir da possibilidade de realização do Exame Nacional do Ensino Médio (ENEM). A apresentação da leitura produzida sobre este processo consistiu na construção de um performance em que um cenário foi montado. Nos corredores do auditório da Universidade, o grupo montou grades de papel, indicando o encarceramento. No altar, eles montaram totens em que colaram imagens diversas e escritas com os depoimentos dos internos. Em pontos estratégicos da plateia, sentaram-se componentes do grupo que, em diferentes momentos levantaram-se e leram depoimentos dos internos. Em seguida, um dos estudantes declama um poema Cântico Negro, de José Regio. Ao final alguns estudantes arrancam com força os papéis que representavam as grades.

A segunda produção, Grupo 2, teve como resultado uma fotonovela sobre o Sr. Saresp. O grupo produziu a fotonovela a partir da reflexão pautada sobre o Sistema de Avaliação do Rendimento Escolar do Estado de São Paulo. Os alunos representaram diferentes personagens do cotidiano escolar e criaram o que denominaram de Sr. Saresp. Este chega à escola para conversar com a diretora. A Professora fica surpresa com tal visita que se dirige aos alunos para falar dos benefícios do sistema de avaliação, entre eles os prêmios como notebooks, pen drive, etc. Para a professora ele se recorda do décimo quarto salário proveniente do bom desempenho dos alunos. Também há uma referência aos pais que acabam tendo acesso aos dados da escola. Ao final, há a referência à frustração pelos prêmios não recebidos.

O Grupo 3 produziu um telejornal em que os jornalistas entrevistam alunos do Ensino Médio sobre o que viveram no ENEM. Ao representarem as alunas construíram um perfil de aluno totalmente alienado em relação ao processo e outro estudante do ensino médio produziu um discurso menos alienado. A âncora fazia referências ao que era o processo de avaliação do ENEM. No telejornal também havia um quadro sobre o clima em que a estudante que representou a "Jornalista do tempo" construiu um discurso sobre o clima que se referia à situação do Sistema de Avaliação do Ensino Médio.

Olh@res, Guarulhos, v. 2, n. 1, p. 253-269. Maio, 2014. 
O Grupo 4 produziu um vídeo que constava de duas partes: a primeira era a propaganda do governo sobre a Prova Brasil. Bem humorado, um dos estudantes do grupo representou a apresentadora de dados oficiais sobre a Prova Brasil. O outro vídeo foi um documentário de como dois jovens de classes sociais distintas chegam até a escola. Ele mostra as intempéries vividas pelos estudantes de classe menos favorecida, como acordar cedo, pegar ônibus, ser vítima de assalto, enquanto o outro estudante representado era de classe média, tomava um belo café da manhã e seu pai o levava para a escola de carro. A partir desta diferenciação, os dois enfrentam situações distintas na escola, em seus processos de aprendizagem. Os dois vídeos são apresentados ao público num formato de debate entre um especialista no campo educacional e um representante do governo Federal. O primeiro vídeo foi postado no youtube, com o título PPP 2013 - Ufscar Sorocaba: Vídeo IDEB e o comentário de quem o postou é o seguinte: Uma releitura cômica do comercial do MEC, para esclarecer e promover a política de metas para a educação.

O Grupo 5 apresentou as entrevistas realizadas com alunos do ensino Médio sobre a experiência de realização do ENEM. Ao longo da transmissão das entrevistas, as estudantes recortaram reflexões de autores do campo da avaliação estudados e que se aproximavam dos recortes das entrevistas produzidos.

O Grupo 6 produziu um documentário, tomando o estilo do curta-metragem "Ilha das Flores"4 como referência, em que há uma breve retomada histórica do processo de formação da educação escolar até chegar aos processos de avaliação no interior da escola. Ao longo da produção há inserções em diferentes perspectivas históricas também no campo econômico, como o nascimento do capitalismo e sua relação com a educação escolar, dentre outras questões. Ao finalizar com a inserção da Prova Brasil no documentário, os estudantes optaram por trazer frases das crianças entrevistas, ao som de (?). Este documentário também foi postado no YouTube com o título Quantidade não é Qualidade e quem o postou assim o

\footnotetext{
${ }^{4}$ Curta metragem produzido por Jorge Furtado (1986).

Olh@res, Guarulhos, v. 2, n. 1, p. 253-269. Maio, 2014.
} 
definiu: Documentário Quantidade não é qualidade, faz uma reflexão sobre o uso que é feito do espaço escolar desde a Grécia antiga até hoje e como as políticas econômicas, como o neoliberalismo, influência o ambiente escolar. O Documentário foi feito para a disciplina de Pesquisa e Praticas Pedagógicas IV.

O Grupo 7 apresentou os discursos dos alunos dos anos iniciais do ensino fundamental. Para tanto as vozes das crianças foram reproduzidas em tom alto enquanto o auditório estava num ambiente escuro. Depois de apresentarem estas falas, acenderam as luzes e conversaram com a plateia sobre o trabalho de coleta de dados realizado.

Após esta breve descrição de cada um das produções, gostaríamos de fazer algumas leituras das produções, com o objetivo central de indiciar como entendemos que os alunos definiram avaliação em suas apresentações. Não temos com isto a intenção de esgotar, nem tampouco rotular suas formas de ver e pensar a avaliação educacional. O que pretendemos, aqui, é pontuar o que nos chamou a atenção neste processo e refletir a respeito das representações dos alunos sobre os processos de avaliação após a finalização do trabalho. Para tanto vale retomar dois grupos que nos chamaram a atenção.

O primeiro deles foi o grupo 1. Ao relatarem, pela forma de performance teatral, o que foi o processo do ENEM para os internos de um presídio, demonstraram, em seus discursos, o quanto ele pode ser um mecanismo de construção de estímulo à sua autoestima. Em um dos depoimentos de interno reproduzido na apresentação ele diz o seguinte "já me senti parte da sociedade por fazer a prova do ENEM". Um homem que se encontra no limite de sua desumanidade (estar privado do seu direito de liberdade), ao realizar a prova que milhares de pessoas em liberdade também a elaboram, se sente igual aos outros, pelo menos naquele momento.

O ENEM está sendo compreendido, nesta situação, como um mecanismo de se pautar socialmente, de se inserir socialmente. É por seu meio que conseguem ascender em seus estudos. Os estudantes de Pedagogia, ao trazerem este discurso, nos fazem refletir sobre as diferentes nuances que tomam os processos de avaliação por diferentes sujeitos. São sentidos

Olh@res, Guarulhos, v. 2, n. 1, p. 253-269. Maio, 2014. 
diversos oriundos da participação neste exame. Ao fazerem a escolha de trazer tal discurso para a apresentação, demonstram que, apesar das críticas aos sistemas de avaliação, a sua realização precisa ser tomada também pela leitura das subjetividades dos sujeitos envolvidos. Não estamos com isto defendendo a continuidade ou descontinuidade dos processos de avaliação em larga escala, mas a necessidade de compreensão de seus sentidos e suas potencialidades para diferentes sujeitos.

Vale retomar outro dado apresentado pelo grupo que é o de que, com a participação na prova do ENEM, o interno tem a possibilidade de redução de pena. O sistema de avaliação que, em muitos casos, tem a função de classificação, aqui serve como um mecanismo de possibilidade de sair de uma situação de risco ainda maior a que eles já estão expostos. Desta forma, este grupo nos aponta as contradições dos processos de a valiação.

Diferentes do grupo 1, se apresentam o grupo 2 e 4 . O grupo 2 demonstra como o sistema de avaliação incentiva a meritocracia no interior da escola quando problematiza o bônus, os prêmios para alunos e os altos índices da escola como propaganda de governo. Demonstra, assim, como a meritocracia percorre os diferentes níveis pelos quais as avaliações perpassam. Os alunos ganham prêmios, o professor ganha bônus, a escola sobe no índice e o governo ganha status. Demonstra também a continuidade da não aprendizagem.

Afonso (1999) discute a presença do Estado avaliador no ensino, subsidiando uma política de competição e de pressão sobre as escolas e professores, através da realização dos exames e testes estandardizados, que agem como dispositivos de regulação dos sistemas de ensino.

A prática da avaliação em larga escala tem se consolidado na perspectiva do accountability, o que oportuniza diferentes críticas e debates. Os alunos, a direção e os professores se encontram circunscritos num processo de "prestação de contas" a partir de uma matriz de referência, buscando o aperfeiçoamento para o alcance de metas e objetivos. Muitas escolas reorganizaram o currículo desenvolvido em prol das exigências dessas matrizes, inclusive trabalhando apenas as disciplinas que são avaliadas (língua portuguesa e matemática). Entretanto, no que diz respeito às 
políticas públicas, poucas são as iniciativas que auxiliem o trabalho pedagógico, no que tange à formação, apoio, recursos materiais e financeiros.

Não basta avaliar os aspectos cognitivos dos alunos, sucumbindo outras dimensões que fazem parte do processo educativo. Nesta perspectiva, o grupo 4 fez uma leitura em que demonstram o quanto as condições da família influenciam o processo de aprendizagem e seu impacto sobre as avaliações. A leitura deste grupo nos leva a refletir sobre como os processos de avaliação desconsideram as realidades vividas pelos sujeitos envolvidos no processo de aprendizagem no interior da escola. O que, de certa forma, nos conduz a pensar então que: há a necessidade também de olhar para as necessidades pessoais, entretanto superar a teoria da carência cultural que afeta o desempenho; há a necessidade de redimensionar a estrutura escolar e as formas de ser temporal e espacialmente. A teoria da carência cultural pode nos levar a compreender o fenômeno do mau desempenho como dependente apenas das condições socioeconômica da escola, desconsiderando o fazer escolar $\mathrm{e}$ as potencialidades da escola no desenvolvimento de sua função última, a de trabalhar com a transformação dos sujeitos.

\section{Algumas palavras finais}

O tema avaliação, ainda suscita muitas polêmicas e reflexões, principalmente, no contexto atual marcado pelas atividades avaliativas em larga escala. Por se tratar de algo muito abrangente, a avaliação envolve diferentes áreas e concepções e torna-se arena de contradição e conflito ideológico.

Buscando desenvolver um trabalho na contramão da lógica da exclusão e classificação (características marcantes da avaliação nos contextos escolares), a proposta de trabalho planejada aos alunos de Pedagogia UFSCAR (Sorocaba) elencou como objetivos a compreensão da relação entre o contexto social e as dimensões educacionais; reflexão sobre diferentes instrumentos e procedimentos de avaliação escolar; e, a Olh@res, Guarulhos, v. 2, n. 1, p. 253-269. Maio, 2014. 
identificação das iniciativas de avaliação em larga escala, relacionando-as ao desenvolvimento do trabalho escolar. O trabalho nos permitiu abordar nossa implicação nesse processo como formadores de professores, formadores e perpetuadores ou não da lógica da exclusão.

As leituras, as discussões e as narrativas trabalhadas nos diferentes encontros das disciplinas, oportunizaram reflexões sobre a complexidade do processo de ensino e aprendizagem, circunscrito por inúmeras dimensões. Destacamos a avaliação como tema central, vislumbrando possibilidades de planejar e desenvolver uma proposta pedagógica menos excludente, considerando as condições sociais, históricas e econômicas.

Essa proposta de avaliação vê alunos e professores numa perspectiva de desenvolvimento, de devir. Ou seja, percebe a escola como possibilidade de construção coletiva, de um trabalho que compreenda os limites, as contradições, mas que articule as ações numa dimensão de intervenção com vistas à superação. Isso não exime o poder público de suas obrigações, no que se refere às condições de trabalho e educação.

A ideia de articular a pesquisa de campo às discussões realizadas no contexto da universidade nos permitiu pensar nos múltiplos significados e sentidos da avaliação, extrapolando, também, o âmbito escolar. Os impactos negativos, pejorativos, discriminatórios foram abordados e percebidos nos diferentes discursos. E, atualmente, verificamos outros sentidos para essa ação: punição, seleção, classificação não só para alunos, mas para escolas que se encontram marcadas pelas avaliações externas.

Responsabilizar-se e "prestar contas" do seu trabalho! É dessa maneira que a escola atual se percebe nesse novo contexto.

Sabemos das responsabilidades e dos compromissos políticos das escolas e dos professores. Não queremos escamotear essas questões! Porém, nessa lógica de avaliação em larga escala, parece que não há responsabilidade referente às políticas públicas e ao Estado (FREITAS, 2007). Essa responsabilização é bilateral! Não há como culpabilizar apenas um dos polos (a escola). 


\section{Referências}

AFONSO, A. J. Avaliação Educacional: regulação e emancipação. São Paulo: Cortez Editora, 1999.

FREITAS et. alii. Avaliação Educacional: caminhando pela contramão. São Paulo: Editora Vozes, 2009. (Coleção Fronteira Educacionais)

FREITAS, L.C. Eliminação adiada: o ocaso das classes populares no interior da escola e a ocultação da (má) qualidade do ensino. Educ. Soc., Campinas, vol. 28, n. 100 - Especial, p. 965-987, out. 2007

FREITAS, L.C. Ciclos, seriação e avaliação: confronto de lógicas. São Paulo: Moderna, 2003

GATTI, B.A. Avaliação de sistemas educacionais no Brasil. Sísifo. Revista de Ciência da Educação, n. 9, mai/ago 2009, p. 7-18.

GALLO, S. Transversalidade e educação: pensando uma educação não-disciplinar. IN ALVES, N. Sentido da Escola, Rio de Janeiro: DP\&A, 2000.

HOFFMAN, J.M.L. Avaliação mediadora: uma relação dialógica na construção do conhecimento, 2000.2 Disponível em< http://www.crmariocovas.sp.gov.br/pdf/ideias_22_p051-059_c.pdf > Acesso em 22/09/2012. LUCKESI, C.C. Avaliação da aprendizagem escolar. São Paulo: Cortez, 1995.

LÜDKE, M.; ANDRÉ, M. E. D. A. Pesquisa em educação: abordagens qualitativas. São Paulo: EPU, 1986.

MORIN, E. Articular Saberes. IN ALVES, N. Sentido da Escola, Rio de Janeiro: DP\&A, 2000.

MORIN, E. Articular Saberes. IN ALVES, N. Sentido da Escola, Rio de Janeiro: DP\&A, 2000 .

POMBO, Olga. Interdisciplinaridade: conceito, problemas e perspectivas, s/d. Disponível em http://cfcul.fc.ul.pt/textos/textosdisponiveis.htm. Acessado em junho/2011 